\title{
The Validation Process of the Method of Balancing Gas Contained in the Pore Space of Rocks via Rock Comminution
}

\author{
Mateusz Kudasik, Anna Pajdak, Norbert Skoczylas \\ kudasik@img-pan.krakow.pl; pajdak@img-pan.krakow.pl; skoczylas@img-pan.krakow.pl \\ The Strata Mechanics Research Institute of the Polish Academy of Sciences \\ Reymonta 27, 30-059 Cracow, Poland
}

\begin{abstract}
The article discusses the validation process of a certain method of balancing gas contained in the pore space of rocks. The validation was based upon juxtaposition of the examination of rocks' porosity and the effects of comminution in terms of assessing the possibility of opening the pore space. The tests were carried out for six dolomite samples taken from different areas of the 'Polkowice-Sieroszowice' copper mine in Poland. Before the rock material was ground, it was examined using the porosimetric method and subsequently subjected to the SEM analysis. After grinding, the research material was subjected to the granulometric analysis. Prior to the grinding process, the rocks' porosity fell in the range of $0.3-14.8 \%$, while the volume of the open pores was included in the $0.01-0.06 \mathrm{~cm}^{3} / \mathrm{g}$ range. The research material was also characterized by inhomogeneous distribution of the pore volume. The grinding process was performed using an original device - the GPR analyzer. The ground samples were characterized by similar particle size distribution and mean diameters $D_{3.2}$ of about 4.0-4.5 $\mu \mathrm{m}$. The SEM analysis revealed pores of various size and shape on the surface of the rock cores, while at the same time demonstrating lack of pores following the grinding process. The grain size distribution curves were compared with the cumulative pore volume curves of the cores before grinding. The resulting intersection points of both curves were seen as testifying to the presence of openings in the rock pores and release of the accumulated gas. The opening percentage of the pore space was associated with the coordinates of the curves' intersections. In order to confirm the argument put forward in this paper - i.e. that comminution of a rock to grains of a size comparable with the size of the rock's pores results in the release of gas contained in the pore space - the amount of gas released as a result of the comminution process was studied. The results of gas balancing demonstrated that the pore space of the investigated dolomites was filled with gas in amounts from $3.19 \mathrm{~cm}^{3} / \mathrm{kg}$ to $45.86 \mathrm{~cm}^{3} / \mathrm{kg}$. The obtained results of the rock material comminution to grains comparable - in terms of size - to the size of the pores of investigated rocks, along with asserting the presence of gas in the pore space of the studied dolomites, were regarded as a proof that the method of balancing gas in rocks via rock comminution is correct.
\end{abstract}

\section{Keywords}

porosity; gas; outburst; dolomite, copper ore mines.

\section{Introduction}

The gasogeodynamic threat in mining, connected with the coexistence of gaseous and solid minerals, is usually associated with the presence of methane $\left(\mathrm{CH}_{4}\right)$ or carbon dioxide $\left(\mathrm{CO}_{2}\right)$ in coal deposits. Gas can occur in rocks in the following forms: adsorbed, absorbed, dissolved and free [1,2]. Gas occurring in rocks under a considerable pressure value becomes a source of energy, which is the main cause of gas and rock outbursts [3-5]. A necessary condition for the initiation of an outburst is an instance in which the work necessary to crush the rock is smaller than the gas energy. If these parameters are similar, an outburst will be initiated, but its progress will be stopped. For an outburst to be able to develop, continuous transportation of the outburst mass is necessary, 
which, in turn, requires a supply of another portion of energy. Thus, for a full outburst to occur, the energy of the gas accumulated in the rock crevices and pores should be such as to be able to crush the rock material and transport it along the excavation.

In the case of coal, the mechanisms responsible for an outburst initiation and transportation of the outburst mass are broadly described [6-11]. The pore pressure of methane, along with coal's tensile strength, determine the energy of outburst initiation [12]. The transport description most often presupposes a fluidized movement of the outburst mass with a continuous supply of the gas factor as a result of an intensive desorption of the gas from finely ground coal [13]. Indirectly, by sorption isotherm, the pore pressure determines the content of sorbed $\mathrm{CH}_{4}$ or $\mathrm{CO}_{2}$ in coal, whereas additional knowledge of porosity makes it possible to specify the amount of free gas. There are a lot of methods of assessing outburst hazard in coal seams but they are most often based on desorbometric measurements or the amount of methane juxtaposed with a chosen strength parameter $[8,14]$.

When analysing the gas-rock system, it is difficult to find significant similarities between coal and dolomites. The mechanisms of accumulation and transportation of gas in the pore space of these two types of rock differ considerably [15-18]. Dolomites are virtually impermeable to gas [19,20]. Moreover, if diffusion and sorption occur in these rocks, they do so to a small extent. It is in contrast with good sorption properties of coal (gas capacity: dolomite $<0.1 \mathrm{~cm}^{3} / \mathrm{g}$, hard coal $1-20 \mathrm{~cm}^{3} / \mathrm{g}$ ) and complex mechanisms of gas transportation within the coal matrix. The gas contained in copper-bearing rocks is free gas located in the pore space. What is more, dolomites are characterized by higher firmness (dolomite 8-10, coal $<1.5$ ), higher density (dolomite 2.7-2.9 $\mathrm{g} / \mathrm{cm}^{3}$, hard coal 1.1-1.8 g/ $\mathrm{cm}^{3}$ ) and higher strength (e.g. compression strength: dolomite 50-300 MPa, hard coal $<15 \mathrm{MPa}$ ) [21,22], which translates into difficulties with effective comminution of these rocks. These differences do not allow for direct application of methods of gas content assessment in coal in order to analyze the amount of gas in dolomites.

Gasogeodynamic phenomena in copper mines are much rarer, and thus less analyzed. In September 2009, in T-169a drift in 'Rudna' copper mine, an outburst of gas and dolomite took place. It was the first such incident in the world [23-25]. Due to significant differences between a dolomite outburst and a coal outburst, the application of methods and tools for defining the metrological parameters used to assess the outburst hazard in coal mining is impossible. The main differences between coal and dolomite, affecting the occurrence of gasogeodynamic phenomena, derive from differences in the chemical composition of the two rocks, their sorption properties, as well as physical and mechanical properties.

Dolomite, as a rock formation, consists predominantly of mineral dolomite $\left(\mathrm{CaMg}\left(\mathrm{CO}_{3}\right)_{2}\right)$, and - as it rarely occurs in the natural state in its pure form - it is often accompanied by the presence of calcite $\left(\mathrm{CaCO}_{3}\right)$ and other minerals formed as iron compounds $\left(\mathrm{FeS}_{2}\right)$, magnesium $\left(\mathrm{MgCO}_{3}\right)$ and silicon dioxide $\left(\mathrm{SiO}_{2}\right)$. It is a massive, firmly built rock of poor structural diversity and poorly developed porosity [24]. Due to the nature of dolomite deposits, it includes both open and closed pores [26]. According to the classification of the International Union of Pure and Applied Chemistry [27], from the point of view of the size of the pores in dolomite, mesopores with the diameter in the range of $0.002-0.050 \mu \mathrm{m}$ and macropores with the diameter exceeding $0.050 \mu \mathrm{m}$ are dominant. The pores are of various sizes and shapes. They can act as transporters of gases in rock strata, or they can be spaces without any contact with the environment. Our microscopic observations of the dolomite porosity distribution indicate that the sizes and shapes of open and closed pores are similar (Fig. 1) [24-25]. 


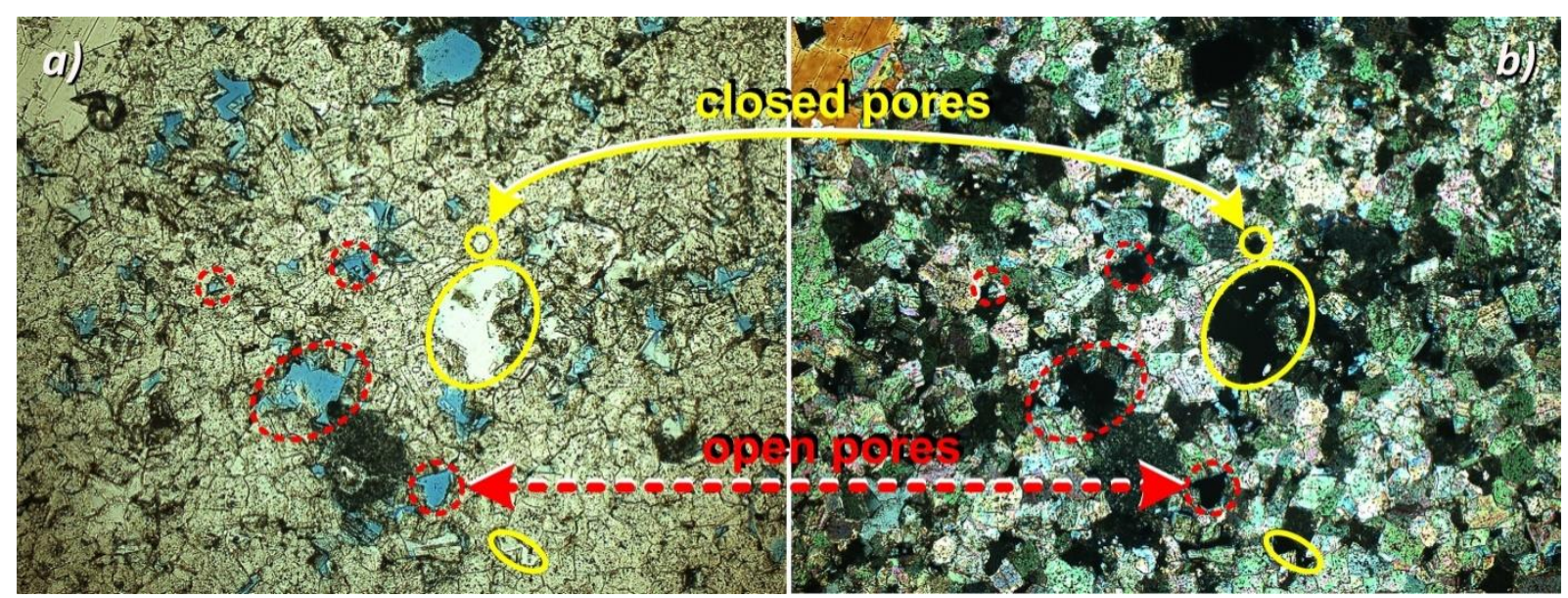

Fig. 1 Epigenetic, porous dolomite with a dominant trans-crystalline porosity. Transmitted light, colored cut, a) one Polaroid (1N), b) two crossed Polaroids (NX), magnification 200x

According to the scarce available studies of the dolomite deposits coming from the region where the outburst of gas and dolomite in 'Rudna' copper mine took place in 2009, closed pores constituted nearly a half of the dolomite's porous structure [23]. It was estimated that the porous pressure of the gas there may have reached up to $10 \mathrm{MPa}$, posing a potential threat and being one of the main causes of the gas and dolomite outburst.

The prevention policy to combat gasogeodynamic phenomena in the mining industry includes determining the gas capacity of rock strata $[14,28,29]$. The basic method of evaluation of the amount and composition of the gas contained in the pore space of a rock is releasing the gas by grinding the tested material. In order to release all the gas contained in the pore space of the rock, it is necessary to grind the rock to the grain size comparable to the size of the pores. Stereological tests of the dolomite rock samples coming from 'Rudna' copper mine showed that the size of the pores was not bigger than $200 \mu \mathrm{m}$ [23]. If, as a result of grinding, the diameter of the rock grains approximates the size of the closed pores, almost all the gas contained in the rock is released. Presuming that the sizes of the closed pores and open pores are statistically comparable, the evaluation of the effectiveness of the comminution of the rock material in terms of releasing the gas contained in its pore space is possible by comparing the grain size distribution obtained by grinding with the pore size distribution of the rock sample before grinding. The results of such a comparison are three hypothetical cases (Fig. 2):

I. The diameter of the largest pores is smaller than the diameter of the smallest grains. In such a case, the comminution of the rock material does not guarantee the opening of its pore space and releasing the gas contained in it.

II. The diameter of the largest grains is smaller than the diameter of the smallest pores. In such a case, the comminution of the rock material guarantees the opening of its pore space and releasing the gas contained in it.

III. The diameters of the pores are comparable to the diameters of the grains. In such a case, the comminution of the rock material may guarantee the opening of its pore space and releasing all or part of the gas contained in it. The amount of the released gas depends on the coordinates of the intersection points $A\left(d_{A}, c_{A}\right)$ of the size distribution curves. 


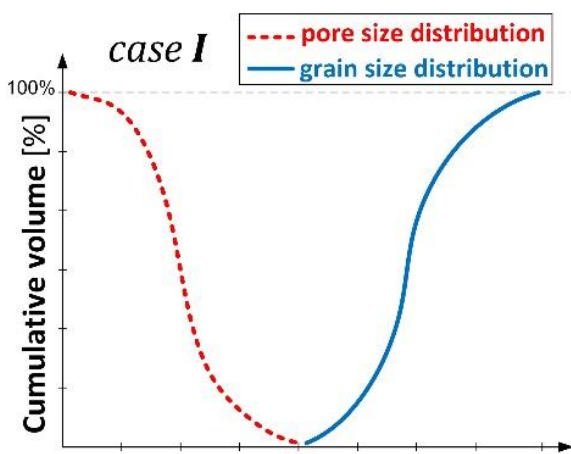

Diameter $[\mu \mathrm{m}]$

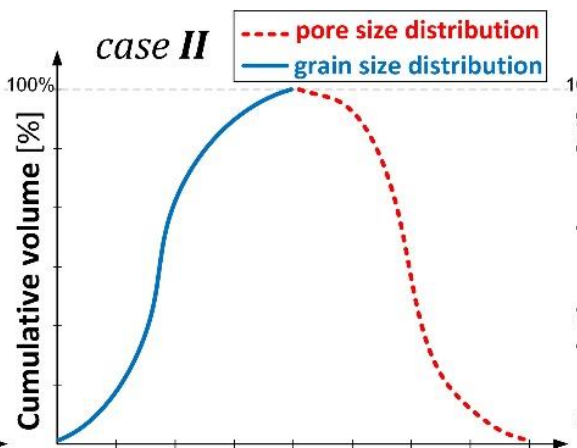

Diameter $[\mu \mathrm{m}]$

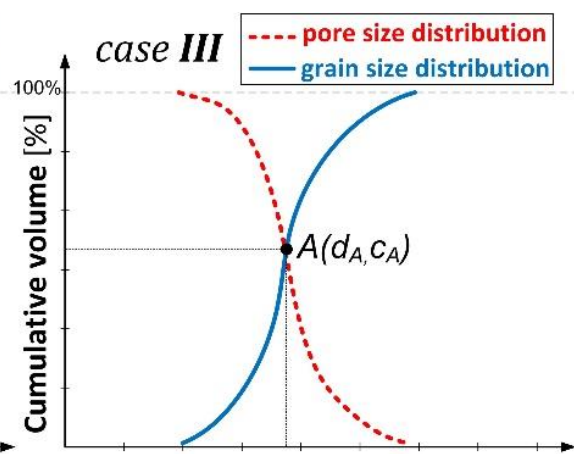

Diameter $[\mu \mathrm{m}]$

Fig. 2 Juxtaposition of the porosimetric and granulometric distribution curves - hypothetical cases

It should be emphasized that the intersection of the curves of the pore size distribution and grain size distribution (case III, Fig. 2) of the tested rock will guarantee releasing a significantly larger amount of gas contained in its pores than the percentage of the pores and the grain sizes in the intersection points of the curves might suggest. The diversity of the grain shapes and pores is huge, and, in the case of the analyses of the pore and grain sizes, their actual dimensions are replaced with the dimensions of solids of revolution. Due to the lack of enclosing rock structure, a grain whose size is similar to the pore in its inside will be broken by the pore pressure of the gas, which, in the case of grains whose size is a few $\mu \mathrm{m}$, exceeds its tensile strength significantly. As a result, the gas contained in the pore space will be released. However, if there is no gas in the grain pores or its amount is small, the releasing of the gas from the point of view of balancing is irrelevant.

The objective of the study was to validate the method of balancing the gas contained in the pore space of rocks via comminution of these rocks. A precondition for the release of the whole amount of gas contained in the rock pore space is comminuting this rock to grains whose size is comparable to the size of pores of the investigated rock. Therefore, the validation of the method of balancing the gas contained in the pore space of rocks was performed by means of comparing the results of the porosimetric studies into a rock sample before its comminution with the results of granulometric studies into an already comminuted sample. In order to evaluate the correctness of the validation process, the amount of gas contained in the pore space of the investigated rocks was balanced. Confirming the presence of gas in the pore space of the investigated dolomites can be considered a proof of the correctness of the method of balancing gas in rocks via comminution of these rocks.

\section{Research material and measurement methods}

The research involved six dolomite rock samples taken from 'Polkowice-Sieroszowice' copper mine in Poland, marked as 1, 2, 3, 4, 5, 6. They were taken from different areas of the mine in the form of cores of $\varnothing 36$ $\mathrm{mm}$ in diameter and the length of about $50 \mathrm{~mm}$. Next, they were crushed to the grain size of 5-30 $\mathrm{mm}$ and divided into two parts:

- lump samples, marked as 1P-6P, respectively,

- ground samples, marked as $1 \mathrm{G}-6 \mathrm{G}$, respectively.

The 1P-6P rock material of the grain size of 5-30 $\mathrm{mm}$ was subjected to the porous structure analysis conducted by means of the porosimetric method using the Pascal mercury porosimeters, including the lowpressure Pascal 140 and the high-pressure Pascal 440. The analysis involved measuring the mercury (Hg) intrusion into the open pores of the rock under strictly controlled pressure in the range of $10^{-5}-10^{-1} \mathrm{MPa}$ (Pascal 140 ) and $10^{-1}-150 \mathrm{MPa}$ (Pascal 440). The researchers measured the volume of the open pores without taking into account the intergranular space and the volume of the closed pores.

Bulk and skeletal density were determined, as well as the percentage of open porosity as calculated from the formula (1): 


$$
\Phi=\frac{\rho_{s k}-\rho_{\text {bulk }}}{\rho_{s k}} \cdot 100 \%,
$$

where:

$\rho_{s k}\left[\frac{\mathrm{g}}{\mathrm{cm}^{3}}\right]-$ is the skeletal density,

$\rho_{\text {bulk }}\left[\frac{\mathrm{g}}{\mathrm{cm}^{3}}\right]-$ is the bulk density,

$\Phi[\%]$ - is the open porosity.

On the basis on the Washburn equation [30], the size of the pore diameter (2), the surface area (3) and the function of the pore size distribution (4) were established:

$$
\begin{gathered}
D_{\text {por }}=-\frac{4 \gamma \cos \theta}{\Delta p}, \\
S=-\frac{1}{\gamma \cos \theta} \int p d V, \\
f=-\frac{d}{d} \frac{V}{\log D_{\text {por }}},
\end{gathered}
$$

where:

$D_{\text {por }}[\mu \mathrm{m}]-$ is the pore diameter,

$S\left[\frac{\mathrm{m}^{2}}{\mathrm{~g}}\right]-$ is the surface area,

$V\left[\frac{\mathrm{cm}^{3}}{\mathrm{~g}}\right]-$ is the open pore volume,

$\gamma\left[\frac{\mathrm{N}}{\mathrm{m}}\right]-$ is the surface tension of mercury,

$\theta\left[{ }^{\circ}\right]$ - is the wetting angle,

$\rho_{s k}\left[\frac{\mathrm{g}}{\mathrm{cm}^{3}}\right]-$ is the skeletal density,

$\rho_{\text {bulk }}\left[\frac{\mathrm{g}}{\mathrm{cm}^{3}}\right]-$ is the bulk density,

$\Delta p[\mathrm{~Pa}]$ - is the difference of the hydrostatic pressure of mercury and the pressure of the gas in the pores.

Due to the mezoporous and macroporous specificity of dolomite and its strong resistance to high pressure, it was assumed that the values of the structural parameters obtained as a result of the porosimetric analysis approximated the actual ones.

Some of the samples 1G-6G were comminuted in the GPR analyzer [31,32], whose prototype was built at the Strata Mechanics Research Institute of the Polish Academy of Sciences (Fig. 3). 


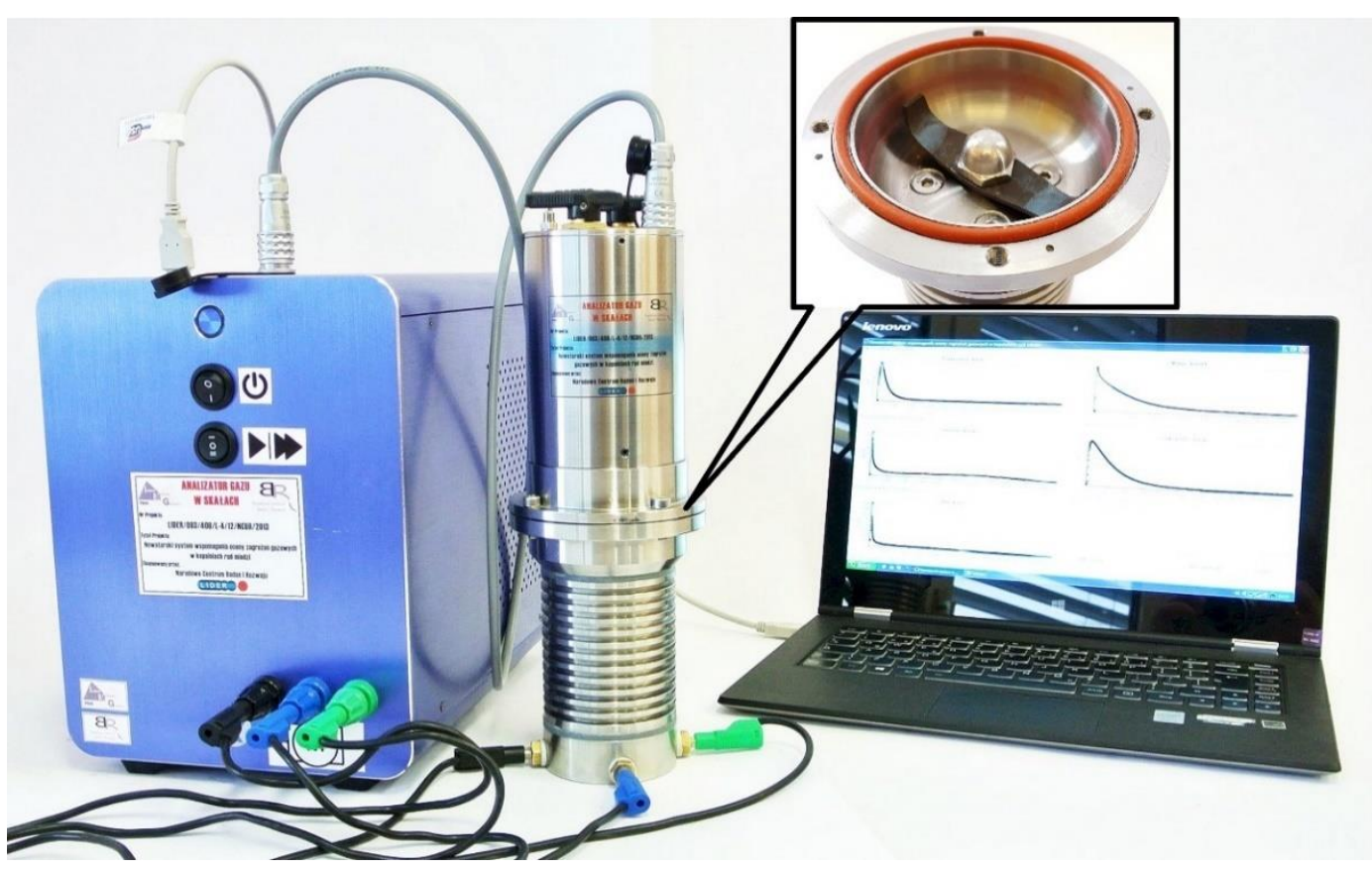

Fig. 3 Analyzer for measuring gas contained in the pore space of rocks: the power supply and data acquisition module (left), the GPR analyzer (middle), the computer with dedicated software (right)

The GPR analyzer works on the principle of an impact mill. A rock sample is placed in a hermetic chamber and crushed by cutting blades, powered by a brushless electric motor. The cutting element is a blade made of tool steel NC11LV. The $2.2 \mathrm{~kW}$ brushless electric motor drives the blade to the maximum rotation speed reaching $21000 \mathrm{rpm}$. The volume of the hermetic chamber is $200 \mathrm{~cm}^{3}$. The upper lid of the measuring chamber of the instrument is equipped with the sensors of gas, pressure, and temperature. The amount of gas contained in the pore space of rocks is balanced based on the change in the pressure of gas in the measuring chamber, which is a result of comminuting the rock sample and releasing the gas included in it. The balance of the amount of gas contained in the rock sample can be established based on the ideal gas law [31]:

$$
\begin{gathered}
\Delta M=\frac{\Delta p_{m} \cdot\left(V_{0}+V_{p}\right)+p_{a t m} \cdot V_{p}}{R \cdot T} \cdot V_{m}, \\
\Delta M \cong \frac{\Delta p_{m} \cdot V_{0}}{R \cdot T} \cdot V_{m}
\end{gathered}
$$

where:

$\Delta M\left[\mathrm{~m}^{3}\right]$ - is the amount of gas contained in the investigated rock sample (under normal conditions),

$\Delta p_{m}[\mathrm{~Pa}]$ - is the change of pressure in the measuring chamber in relation to the reference chamber, resulting from comminuting the sample and the release of gas,

$V_{0}\left[\mathrm{~m}^{3}\right]$ - is the free space surrounding the sample (the volume of the measuring chamber minus the volume of the rock sample),

$V_{p}\left[\mathrm{~m}^{3}\right]-$ is the volume of the closed pores of the rock sample: $V_{p}=\frac{m}{\rho} \cdot \varepsilon$,

$m[\mathrm{~g}]$ - is the mass of the rock sample,

$\rho\left[\frac{\mathrm{g}}{\mathrm{m}^{3}}\right]-$ is the density of the rock sample,

$\varepsilon[-]-$ is the closed porosity of the rock sample,

$p_{\text {atm }}[\mathrm{Pa}]-$ is the atmospheric pressure,

$R\left[\frac{\mathrm{J}}{\mathrm{mol} \cdot \mathrm{K}}\right]-$ is the universal gas constant,

$T[K]$ - is the temperature within the measuring chamber during the measurement,

$V_{m}\left[\frac{\mathrm{m}^{3}}{\mathrm{~mol}}\right]-$ is the molar volume of gas (under normal conditions). 
The initial tests showed that the device was able to crush very firm rock material characterized by high tensile strength, and that crushing rock by impact milling is more efficient than other rock crushing methods $[33,31]$.

Samples weighing 50 grams each were ground for 60 seconds to rock material whose grain size equalled a single $\mu \mathrm{m}$. A longer grinding time did not affect the effectiveness of the comminution process. An image of a demonstration sample before and after grinding is shown in Fig. 4.

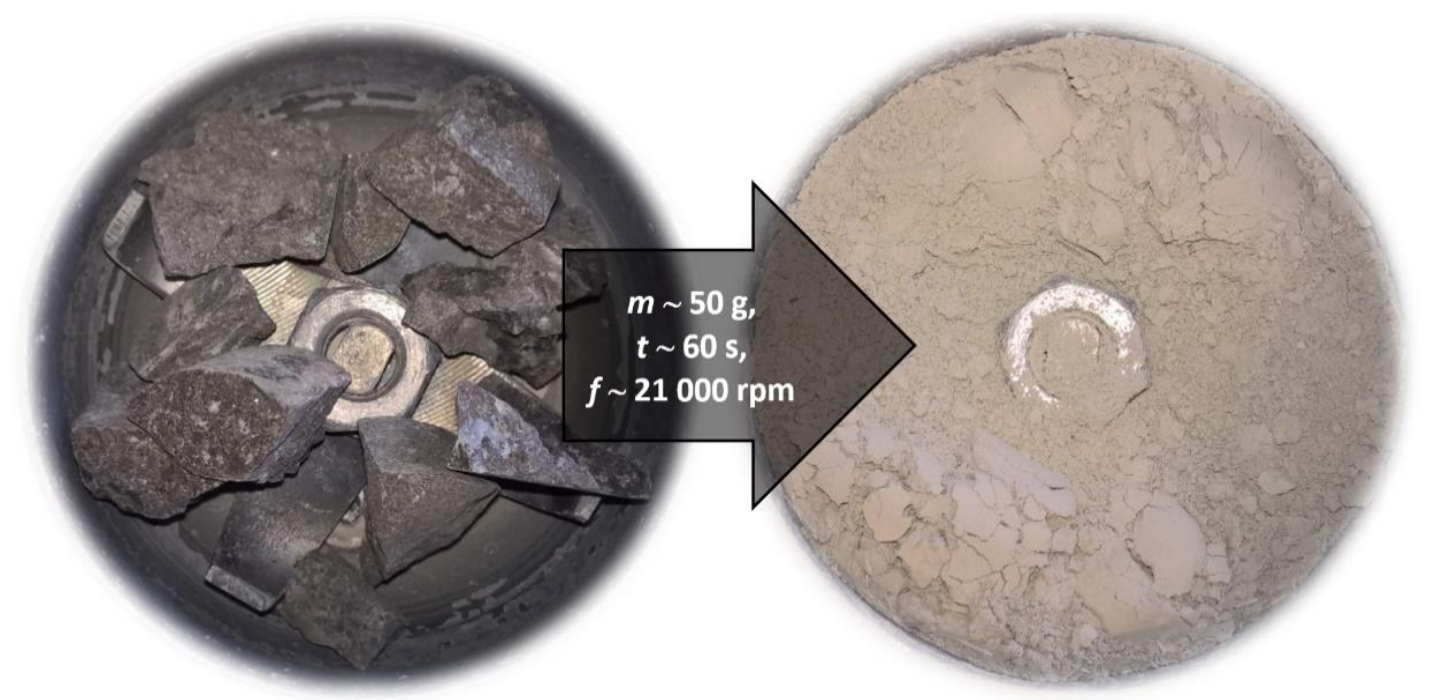

Fig. 4 Images of a demonstration dolomite sample before and after grinding

The ground samples $1 \mathrm{G}-6 \mathrm{G}$ were subjected to a granulometric analysis using a grain size analyzer Mastersizer 2000E. The measurement involved laser beam diffraction of particles measuring 0.1-100 $\mu \mathrm{m}$. The tests were carried out in distilled water dispersion. A built-in ultrasound probe was applied in order to break possible agglomerates. The measurement procedure is compatible with the ISO 13320-1 particle size analysis requirements [34]. To describe the average particle size, the researchers used a substitute diameter of a sphere of the surface equal to an average particle of any shape - the so-called Sauter mean diameter [35], from the following formula:

$$
D_{3.2}=\frac{\sum D_{V}^{3}}{\sum D_{S}^{2}}
$$

where:

$D_{S}[\mu \mathrm{m}]-$ is the surface-equivalent sphere diameter,

$D_{V}[\mu \mathrm{m}]$ - is the volume-equivalent sphere diameter,

$D_{3.2}[\mu \mathrm{m}]-$ is the Sauter mean diameter.

In order to observe the change of the morphology of the surface of the dolomites, the sample displaying the highest porosity was subjected to a scanning analysis using the EDAX Apollo XP electron microscope (SEMEDS). The device is equipped with the EDAX Apollo X energy dispersive X-Ray spectrometer, which uses secondary electrons imaging and backscattered electrons imaging BSE. The latter was used in the analyses. Backscattered electrons have high energy and make it possible to observe the topography of the surface of a sample, as well as to identify its composition.

The measurements were carried out under the electron beam-accelerating voltage of $20 \mathrm{kV}$, which corresponds with the resolution limit in the range of 2.0-2.5 nm. For the purpose of the analyses, polished sections were made. As the samples were not electrically conductive, they were covered with thin silver (Ag) layers in a sputter coater. To prevent possible damage or deformation of the topography of the surfaces of the samples, the 
measurements were performed in the low-pressure mode $\left(10^{-2} \mathrm{~Pa}\right)$. Immediately before the measurement, the samples were purged with compressed air to remove small impurities.

\section{Measurement results}

\subsection{Porosimetric analysis}

The samples varied in terms of porosity, volume and the specificity of structural parameters. Tab. 1 shows the results of the porosimetric analysis.

Tab. 1 Structural properties of dolomites

\begin{tabular}{|c|c|c|c|c|c|c|}
\hline \multirow{2}{*}{ Sample } & $\begin{array}{c}\boldsymbol{\rho}_{\text {bulk }} \\
\mathrm{g} / \mathrm{cm}^{3}\end{array}$ & $\begin{array}{c}\boldsymbol{\rho}_{\text {sk }} \\
\mathrm{g} / \mathrm{cm}^{3}\end{array}$ & $\begin{array}{c}\boldsymbol{D}_{\text {por }} \\
\mathrm{nm}\end{array}$ & $\begin{array}{c}\boldsymbol{\Phi} \\
\%\end{array}$ & $\begin{array}{c}\boldsymbol{V} \\
\mathrm{cm}^{3} / \mathrm{g}\end{array}$ & $\begin{array}{c}\text { S } \\
\mathrm{m}^{2} / \mathrm{g}\end{array}$ \\
\hline $\mathbf{1 P}$ & 2.75 & 2.88 & 0.128 & 4.63 & 0.017 & 0.53 \\
\hline $\mathbf{2 P}$ & 2.85 & 2.86 & 0.130 & 0.35 & 0.012 & 0.37 \\
\hline $\mathbf{3 P}$ & 2.76 & 2.77 & 0.176 & 0.30 & 0.011 & 0.25 \\
\hline $\mathbf{4 P}$ & 2.74 & 2.89 & 0.313 & 5.01 & 0.018 & 0.23 \\
\hline $\mathbf{5 P}$ & 2.44 & 2.86 & 0.923 & 14.75 & 0.060 & 0.26 \\
\hline $\mathbf{6 P}$ & 2.40 & 2.52 & 1.143 & 4.79 & 0.020 & 0.07 \\
\hline \hline Average & $\mathbf{2 . 6 6}$ & $\mathbf{2 . 8 0}$ & $\mathbf{0 . 4 6 9}$ & $\mathbf{4 . 9 7}$ & $\mathbf{0 . 0 2 3}$ & $\mathbf{0 . 2 9}$ \\
\hline
\end{tabular}

The dolomite samples fell in two groups characterized by similar values of bulk density, which is significant from the point of view of porosity [18]. Samples 1P-4P had higher bulk density - in the range of 2.7$2.8 \mathrm{~g} / \mathrm{cm}^{3}$ - and samples 5P-6P had bulk density of about $2.4 \mathrm{~g} / \mathrm{cm}^{3}$. The dolomites differed in terms of porosity, specified according to equation (1), and in terms of the pore volume. In samples $1 \mathrm{P}-4 \mathrm{P}$, the porosity was from 0.3 to $4.8 \%$ and the pore volume was from 0.01 to $0.02 \mathrm{~cm}^{3} / \mathrm{g}$. The smallest textural diversity was identified in samples $2 \mathrm{P}$ and $3 \mathrm{P}$. Their bulk density and skeletal density were very similar and the porosity was about $0.3 \%$. In sample 5P, the porosity was much higher $-14.8 \%$ - and the pore volume was $0.06 \mathrm{~cm}^{3} / \mathrm{g}$. The mean pore diameter (2) in all samples measured $0.13-1.14 \mu \mathrm{m}$, and the surface area was below $1 \mathrm{~m}^{2} / \mathrm{g}$.

Knowing the volume of the mercury intruded into the pores of the rock as a function of hydraulic pressure, the researchers determined the pore size distribution as a function of their diameter (4) and the accumulated density. The results are shown in Fig. 5 and Fig. 6. Samples 1P and 2P had larger surface area than the other samples, and the majority of their pores had the smallest diameters. Almost half of the total pore volume was in the range of the small pores with diameters measuring $0.1-0.4 \mu \mathrm{m}$, and the pore distribution curves had unimodal shape. The majority of pores in samples $3 \mathrm{P}$ and $4 \mathrm{P}$ had diameters measuring from $1 \mu \mathrm{m}$ to $4 \mu \mathrm{m}$. In sample $5 \mathrm{P}$, which had the highest porosity, the majority of the pores had diameters of 6-8 $\mu \mathrm{m}$. In sample $6 \mathrm{P}$, the distribution curve had bimodal shape and two peaks of increased pores volume. This particular sample had the smallest surface area. The majority of the pore space included pores with diameters of 4-8 $\mu \mathrm{m}$ and $20-40 \mu \mathrm{m}$. 


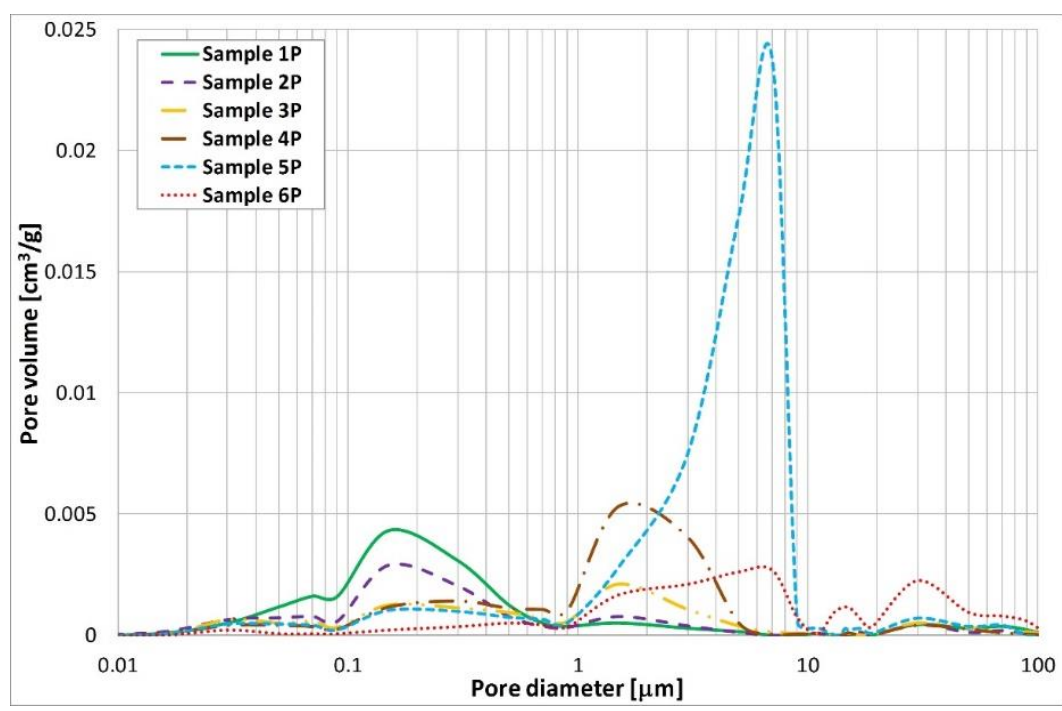

Fig. 5 Pore size distribution curves of dolomites

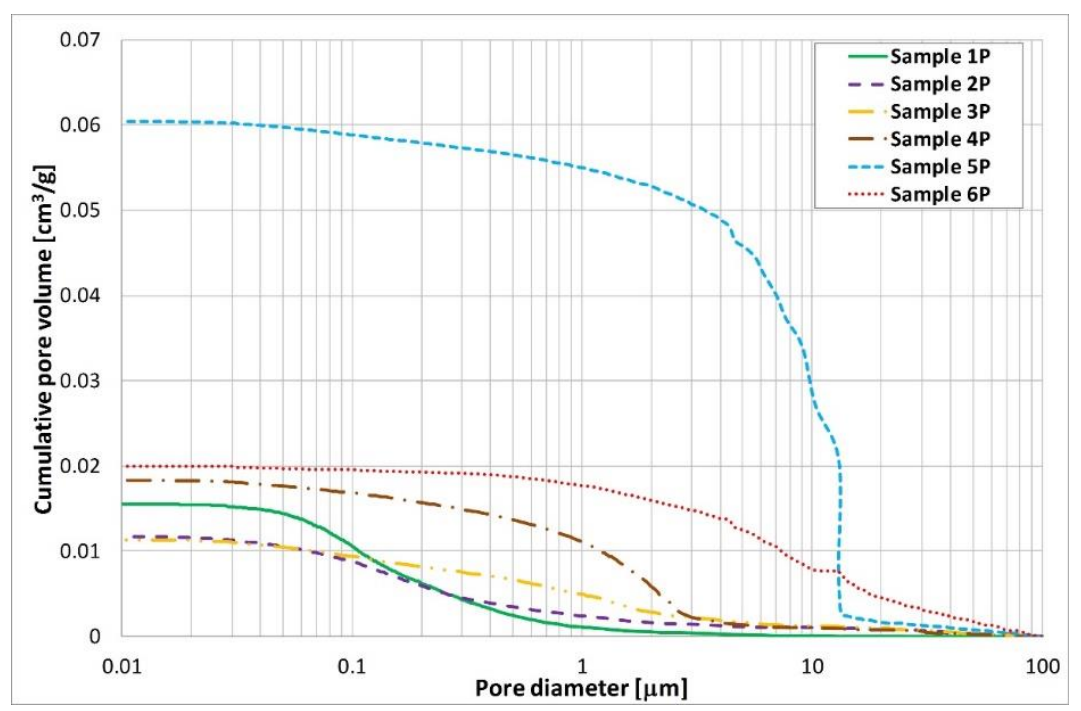

Fig. 6 Cumulative pore volume curves of dolomites

\subsection{Granulometric analysis}

The ground dolomite cores $1 \mathrm{G}-6 \mathrm{G}$ had similar grain distribution curves (Fig. 7). The mean grain diameter $D_{3.2}$ was in the range of 4.0-4.5 $\mu \mathrm{m}$ and the median was from $15.4 \mu \mathrm{m}$ to $18.6 \mu \mathrm{m}$ (Tab. 2). Following the grinding process, the grains were not homogeneous, and grains with diameters of $15-50 \mu \mathrm{m}$ predominated. The boundary values of the grains differed significantly from the mean value, and the grain size distribution was left-skewed. 
Tab. 2 The parameters of the grain distribution of the crushed dolomite rocks $\left(D_{10}-\right.$ is the tenth percentile of the grain diameter distribution, $D_{50}$ - is the median of the grain diameter distribution, $D_{90}-$ is the ninetieth percentile of the grain diameter distribution, $D_{3.2}-$ is the Sauter mean diameter)

\begin{tabular}{|c|c|c|c|c|}
\hline Sample & $\begin{array}{c}\boldsymbol{D}_{\mathbf{1 0}} \\
{[\mu \mathrm{m}]}\end{array}$ & $\begin{array}{c}\boldsymbol{D}_{\mathbf{5 0}} \\
{[\mu \mathrm{m}]}\end{array}$ & $\begin{array}{c}\boldsymbol{D}_{\mathbf{9 0}} \\
{[\mu \mathrm{m}]}\end{array}$ & $\begin{array}{c}\boldsymbol{D}_{\mathbf{3 . 2}} \\
{[\mu \mathrm{m}]}\end{array}$ \\
\hline $\mathbf{1 G}$ & 1.42 & 18.61 & 47.57 & 4.42 \\
\hline $\mathbf{2 G}$ & 1.39 & 15.51 & 55.84 & 4.29 \\
\hline $\mathbf{3 G}$ & 1.29 & 15.48 & 48.22 & 4.11 \\
\hline $\mathbf{4 G}$ & 1.49 & 17.72 & 58.32 & 4.52 \\
\hline $\mathbf{5 G}$ & 1.59 & 18.61 & 62.39 & 4.62 \\
\hline $\mathbf{6 G}$ & 1.43 & 15.44 & 45.17 & 4.34 \\
\hline \hline Average & $\mathbf{1 . 4 4}$ & $\mathbf{1 6 . 9 0}$ & $\mathbf{5 2 . 9 2}$ & $\mathbf{4 . 3 8}$ \\
\hline
\end{tabular}

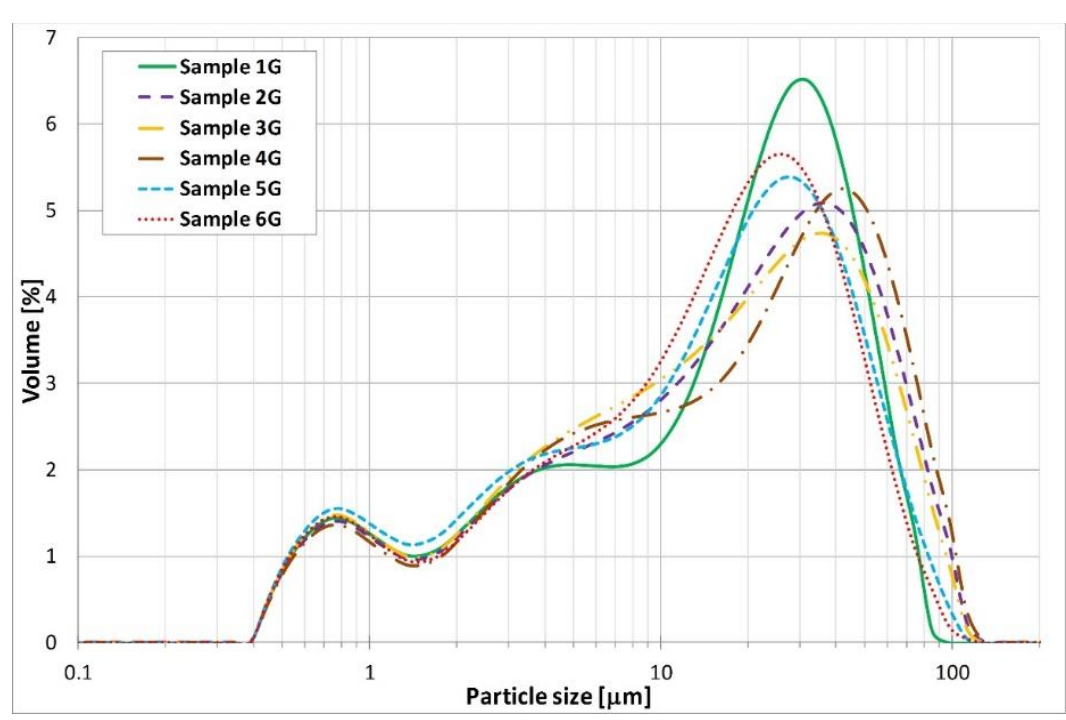

Fig. 7 Grain size distribution of the dolomites

\subsection{Scanning electron microscopy}

Scanning electron microscopy analyses were carried out for the sample of the highest porosity, i.e. 5P, selected in the course of porosimetric analyses. Figure 8 presents the topography of the surface of a lump sample. Numerous small pores of irregular shapes and of irregular distribution can be seen. Their sizes vary, too. The majority of the pores have diameters measuring from a few micrometres to a few dozen micrometres. Pores with diameters larger than a few hundred micrometres occur occasionally. The pores contain well-developed, euhedral and subhedral dolomite crystals of a rhombohedral habit. 


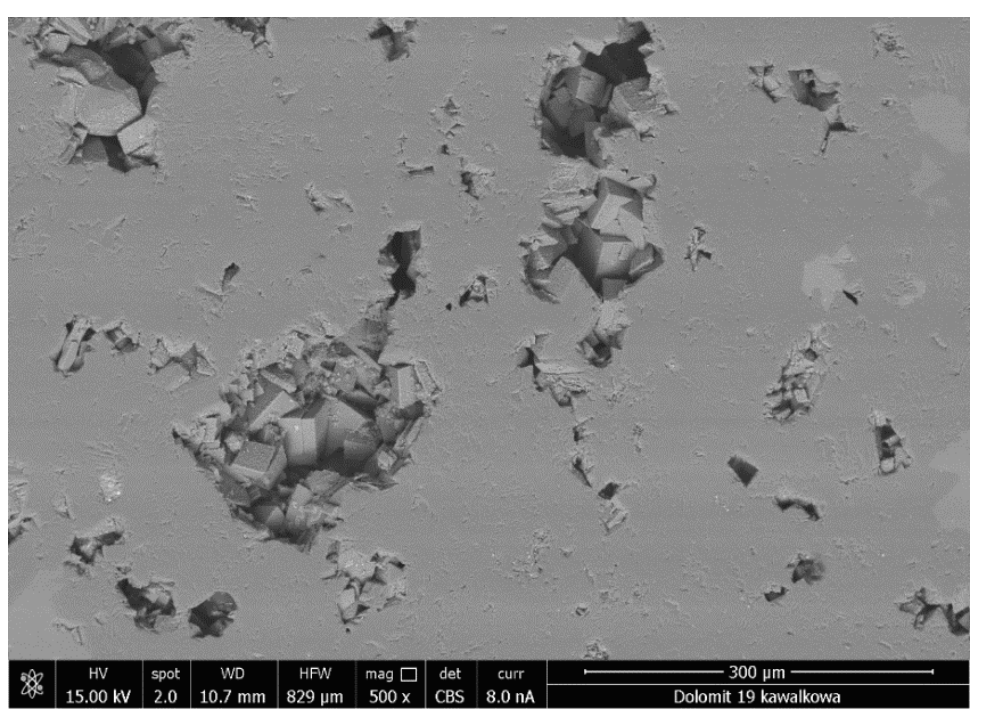

Fig. 8 An image of porous microstructure of dolomite 5P. BSE, mag. 500x

Figure 9 shows a micro-image of sample 5G after crushing. For the purpose of the analysis, the ground dolomite was sieved to the grain fraction below $50 \mu \mathrm{m}$. The visible grains are of various sizes and shapes. Agglomerates of rock fragments adhere to the bigger particles. All the grains have surfaces with slightly visible crystal walls. No pores or cracks can be seen between the crystals.

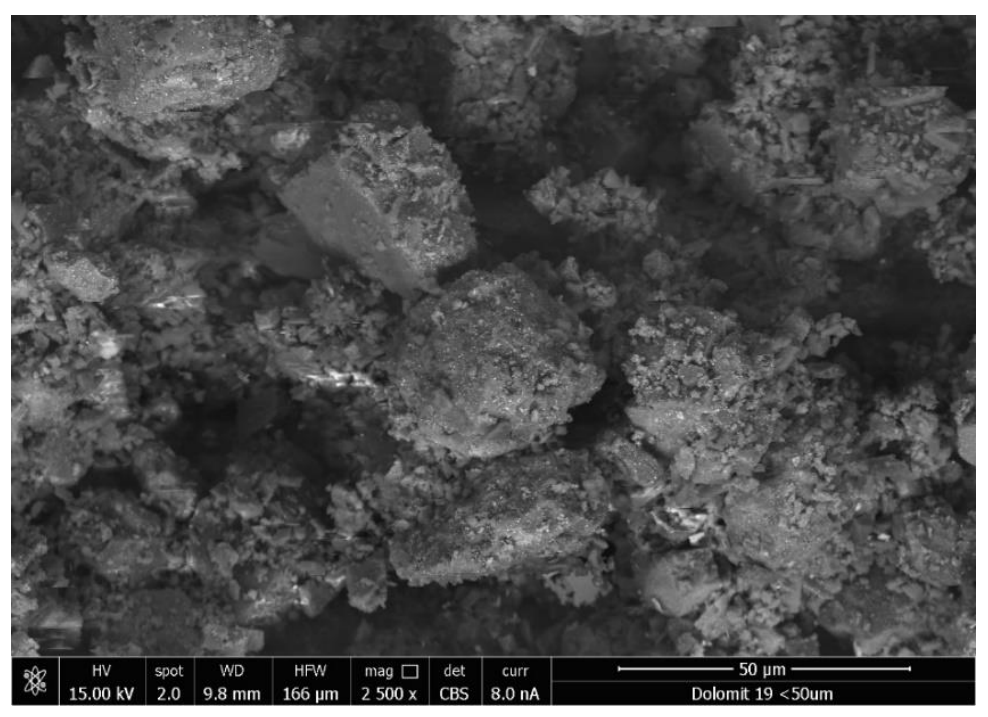

Fig. 9 An image of microstructure of dolomite 5G. BSE, mag. 500x

\subsection{Juxtaposition of porosimetric and granulometric analyses}

Fig. 10 shows the juxtaposition of the curves of the accumulated pore volume of the rock cores $1 \mathrm{P}-6 \mathrm{P}$ with the curves of the grain size distribution curves after crushing $1 \mathrm{G}-6 \mathrm{G}$ samples. It allowed the researchers to assess the extent to which the comminution of the dolomite rocks affected the opening of the pore space. 

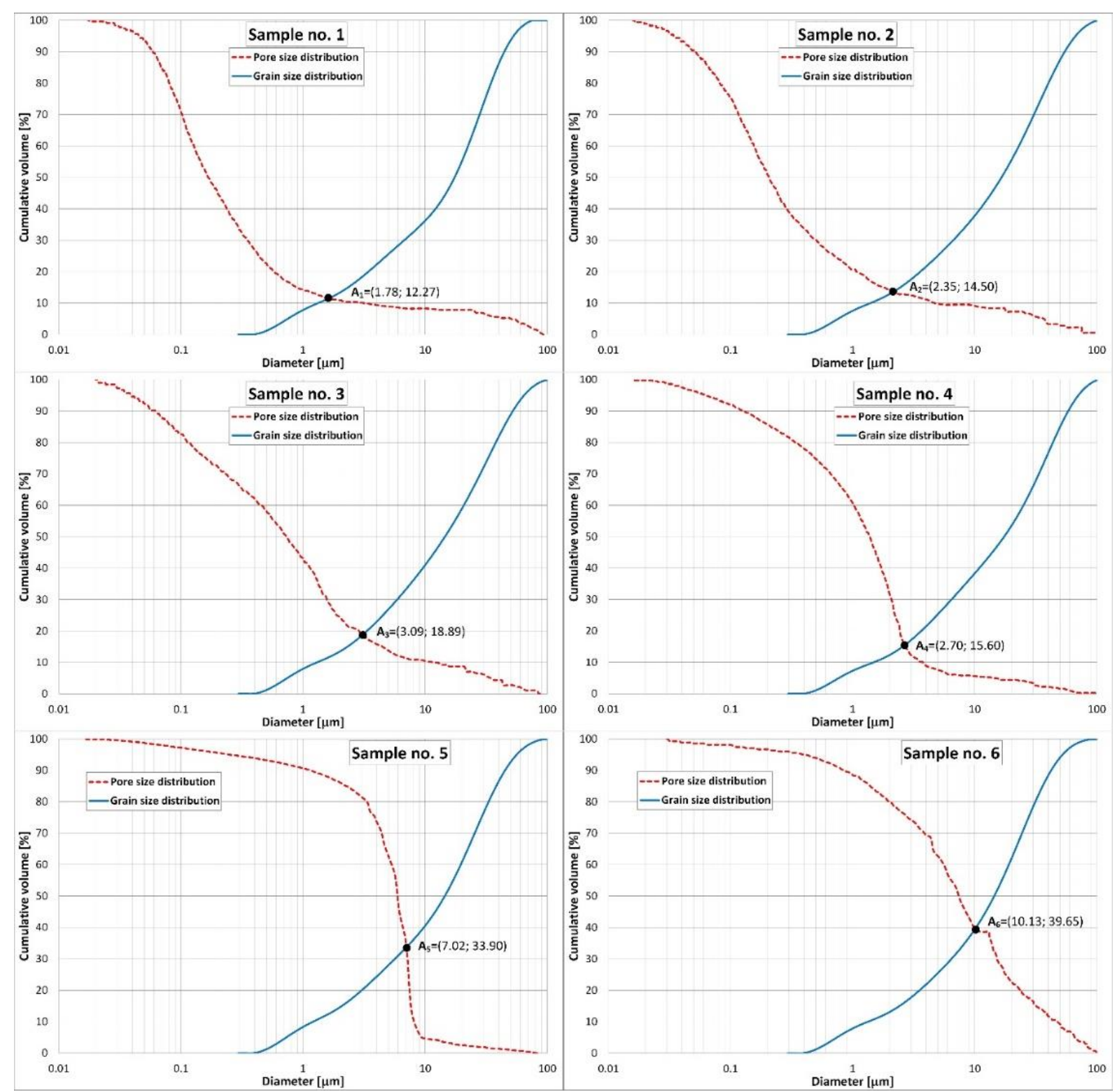

Fig. 10 Juxtaposition of the cumulative curves of the pore distribution and grain size distribution

The shapes of the grain size distribution curves in all the samples after crushing were similar. This was due to similar skeletal density of the samples, as well as the fact that the comminution was conducted under the same conditions. The intersection coordinates were determined mainly by the values of the pore size distribution curves.

In samples 1-4, the pore size distribution curves and the grain size curves intersected in points $A_{1}, A_{2}, A_{3}$ and $A_{4}$, respectively. In these samples, a minor percentage of the smallest grains after crushing $(12.3 \%, 14.5 \%$, $18.9 \%$ and $15.6 \%$, respectively) turned out to have smaller diameters than the largest pores in the core before grinding. In these cases, the grinding process resulted in the porous structure opening to the tune of $12-19 \%$, and this concerned mainly the largest pores whose diameters exceeded $2 \mu \mathrm{m}$.

In samples 5 and 6, the pore size distribution curves and grain size distribution curves intersected in points $A_{5}$ and $A_{6}$. Compared to the other samples before crushing, these samples were characterized by a greater share of large pores, whose diameters exceeded $4 \mu \mathrm{m}$. The intersection points $A_{5}$ and $A_{6}$ indicate that, in these cases, crushing resulted in the opening of the largest pores (i.e. above $10 \mu \mathrm{m}$ ) and of $30-40 \%$ of the total pore space of the rock. 


\subsection{Balance of gas content}

The process of balancing the gas contained in the pore space of the rocks was performed using an original devise known as the GPR analyzer [31,32]. The objective of balancing the gas released from the pore space of the studied rocks was to confirm the correctness of the prior validation. The very fact that gas was identified within the pore space of the rocks can be regarded as a proof of the rock comminution, as well as of releasing the gas contained in the rock. The results of the gas balancing process for the investigated dolomite samples were presented in Table 3. The highest gas content $-45.86 \mathrm{~cm}^{3} / \mathrm{kg}$ - was registered in the case of sample 4G. On the flip side, sample $2 \mathrm{G}$ contained the smallest amount of gas $-3.19 \mathrm{~cm}^{3} / \mathrm{kg}-$ in its pore space. The obtained gas amounts in the dolomite samples approximate the amounts obtained for samples of rocks retrieved from the same area in 'Polkowice-Sieroszowice' copper mine [32].

Tab. 3 The results of balancing the gas contained in the pore space of the investigated dolomite samples

\begin{tabular}{|c|c|} 
Sample & $\begin{array}{c}\text { Gas } \\
\text { content } \\
{\left[\mathrm{cm}^{3} / \mathrm{kg}\right]}\end{array}$ \\
\hline $\mathbf{1 G}$ & 26.26 \\
\hline $\mathbf{2 G}$ & 3.19 \\
\hline $\mathbf{3 G}$ & 29.23 \\
\hline $\mathbf{4 G}$ & 45.86 \\
\hline $\mathbf{5 G}$ & 32.31 \\
\hline $\mathbf{6 G}$ & 31.46 \\
\hline Average & 28.05 \\
\hline
\end{tabular}

\section{Conclusion}

Porous structure is a natural property of rocks and depends on a number of factors. A full description of the porous structure is very important to identify gasogeodynamic phenomena associated with the presence of gas in pores. The main goal of the presented analyses was to assess the degree of opening the pore space of dolomite in the context of balancing the amount and the composition of the gas contained in it. To achieve that goal, the samples were subjected to pore size distribution and grain size distribution analyses. Additionally, studies into balancing the amount of gas contained in the pore space of rocks were conducted.

The porosity of rock samples $1 \mathrm{P}-6 \mathrm{P}$ changed across the $0.3-14.8 \%$ range, but the pore volume, in most cases, was at the level of $11-18 \mathrm{~mm}^{3}$ of the adsorbate per sample gram. Samples $1 \mathrm{P}-4 \mathrm{P}$ had porosity of up to $5 \%$ and unimodal pore distribution. The pores in samples $1 \mathrm{P}$ and $2 \mathrm{P}$ were mostly the lower limit macropores, and samples 3P and 4P had more pores whose diameter ranged from $1 \mu \mathrm{m}$ to $4 \mu \mathrm{m}$. Sample $5 \mathrm{P}$ was characterized by the highest porosity of ca. $15 \%$, i.e. a few times higher than in the case of the other samples. As much as $68 \%$ of that sample's pores had diameters smaller than $6-8 \mu \mathrm{m}$. Sample $6 \mathrm{P}$, with porosity at $4.8 \%$, was characterized by the biggest share of wide pores, and the distribution curve in this case had two peaks of increased-volume pore diameters: at 4-8 $\mu \mathrm{m}$ and at $20-40 \mu \mathrm{m}$. The skeletal density of all the samples fell in the $2.5-2.9 \mathrm{~g} / \mathrm{cm}^{3}$ range, and the surface area was below $1 \mathrm{~m}^{2} / \mathrm{g}$. The mean grain diameter $D_{3.2}$ of the crushed dolomite rocks $1 \mathrm{G}-6 \mathrm{G}$ fell in the range of 4.0-4.5 $\mu \mathrm{m}$, while the median stood at the level of 15.4-18.6 $\mu \mathrm{m}$. After comparing the cumulative pore size distribution and the grain size distribution, it was observed that, in the analyzed samples, the distribution curves intersected in points of up to about $12-40 \%$ of the volume fraction. The intersection points were treated as the indicator of the number of the smallest grains, which, after crushing, were smaller than the biggest pores in the cores before crushing.

The rocks were crushed to the grain size comparable to and smaller than the original size of their pores before crushing. The intersection of the pore size distribution curves and the grain size distribution curves is a 
sufficient condition for the opening of the pore space. The necessary condition is the proximity of the pore size distribution curves and the grain size distribution curves. The great diversity of the pore shapes, as well as that of the grains, guarantees opening more pores than in the case of the sizes of the solids of revolution proposed by the models implemented by the measuring devices and replacing the actual shapes of grains and pores. What is more, the tensile strength of a hypothetical grain, whose size would be comparable with the size of a pore in its inside, would certainly be low enough for the pressure of gas in the pore to break it open.

In order to confirm the correctness of the main assumption of this paper, i.e. that comminuting a rock to grains of a size comparable to the size of the rock's pores results in releasing the gas contained in the rock pore space, an analysis of the amount of gas released following the comminution process was conducted. The results of the balancing of gas demonstrated that the pore space of the investigated dolomites did contain gas to the amount of $3.19 \mathrm{~cm}^{3} / \mathrm{kg}-45.86 \mathrm{~cm}^{3} / \mathrm{kg}$.

The results of the juxtaposition of the porosimetric and granulometric analyses may help to assess gasogeodynamic hazard in copper mines. The applied crushing technology makes it possible for the pore size distribution curves and the grain size distribution curves to intersect, which, in turn, allows us to determine the amount and composition of the gas contained in the dolomite pores. It is true that such a juxtaposition does not provide direct information about the possibility of a rock and gas outburst. However, when accompanied by similar crushing of various copper-bearing rock samples guaranteeing the release of the gas contained in these rocks (cf. Fig. 7), a greater number of bigger pores in one sample (samples 5 and 6; cf. Fig. 10) and similar gas content may mean an increased probability of a gasogeodynamic hazard. This is the effect of the weaker mechanical and strength properties of the porous objects with a greater number of larger pores.

The results of comminuting the rock material to grains of a size comparable to the size of the pores of the investigated rocks, obtained in the course of the research, along with confirming the presence of gas in the pore space of the studied dolomites, were treated as proofs confirming the correctness of the method of balancing gas in rocks via rock comminution.

\section{Acknowledgments}

This work was funded by the National Centre for Research and Development, being part of the project entitled 'An innovative support system for gas hazard evaluation in a copper ore mine' (Project NO LIDER/003/408/L-4/12/NCBR/2013).

\section{References}

1. Mastalerz M., Gluskoter H., Rupp J.: Carbon dioxide and methane sorption in high volatile bituminous coals from Indiana, USA. International Journal of Coal Geology, Vol. 60, 2004, Pages 43-55.

2. Czerw K., Baran P., Zarębska K.: Application of the stretched exponential equation to sorption of mine gases and sorption induced swelling of bituminous coal. International Journal of Coal Geology, Vol. 173, 2017, Pages 76-83.

3. Sobczyk J.: The influence of sorption processes on gas stresses leading to the coal and gas outburst in the laboratory conditions. Fuel, Vol. 90, Issue 3, 2011, Pages 1018-1023.

4. Baran P., Cygankiewicz J., Zarębska K.: Carbon dioxide sorption on polish ortholignite coal in low and elevated pressure. Journal of CO2 Utilization, Vol. 3-4, 2013, Pages 44-48.

5. Baran P., Zarębska K., Nodzeński A.: Energy aspects of $\mathrm{CO} 2$ sorption in the context of sequestration in coal deposits. Journal of Earth Science, Vol. 25, Issue 4, 2014, Pages 719-726.

6. Topolnicki J., Wierzbicki M., Skoczylas N.: Rock and gas outbursts-laboratory tests and in-shaft measurements. Archives of Mining Sciences, Vol. 49, Issue 1, 2004, Pages 99-116. 
7. Wierzbicki M., Młynarczuk M.: Microscopic analysis of structure of coal samples collected after an gas and coal outbursts in the gallery D-6, coal seam 409/4 in the 'Zofiówka' coal mine (Upper Silesian Coal Basin). Archives of Mining Sciences, Vol. 51, Issue 4, 2006, Pages 577-588.

8. Wierzbicki M., Skoczylas N.: The outburst risk as a function of the methane capacity and firmness of a coal seam. Archives of Mining Sciences, Vol. 59, Issue 4, 2014, Pages 1023-1031.

9. Skoczylas N.: Estimating gas and rock outburst risk on the basis of knowledge and experience-the expert system based on fuzzy logic. Archives of Mining Sciences, Vol. 59, Issue 1, 2014, Pages 41-52.

10. Sobczyk J.: A comparison of the influence of adsorbed gases on gas stresses leading to coal and gas outburst. Fuel, Vol. 115, 2014, Pages 288-294.

11. Tian S., Jiang C., Xu L., Yang D., Tang J., Chen Y., Li X.: A study of the principles and methods of quick validation of the outburst-prevention effect in the process of coal uncovering. Journal of Natural Gas Science and Engineering, Vol. 30, 2016, Pages 276-283.

12. Li-ming Q., Xue-xi C.: Analysis on the Influence of Coal Strength to Risk of Outburst. Procedia Engineering, Vol. 26, 2011, Pages 602-607.

13. Zhao W., Cheng Y., Jiang H., Jin K., Wang H., Wang L.: Role of the rapid gas desorption of coal powders in the development stage of outbursts. Journal of Natural Gas Science and Engineering, Vol. 28, 2016, Pages 491-501.

14. Skoczylas N., Wierzbicki M.: Evaluation and management of the gas and rock outburst hazard in the light of international legal regulations. Archives of Mining Sciences, Vol. 59, Issue 4, 2014, Pages 1119-1129.

15. Dürrast H., Siegesmund S.: Correlation between rock fabrics and physical properties of carbonate reservoir rocks. International Journal of Earth Sciences, Vol. 88, 1999, Issue 3, Pages 392-408.

16. Schild M., Siegesmund S., Vollbrecht A., Mazurek M.: Characterization of granite matrix porosity and porespace geometry by in situ and laboratory methods. Geophysical Journal International, Vol. 146, Issue 1, 2001 , Pages 111-125.

17. Pamplona M., Kocher M., Snethlage R.: Halite - A new calibration material for microdrilling resistance measurements. Journal of Cultural Heritage, Vol. 11 Issue 2, 2010, Pages 180-184.

18. Siegesmund S., Snethlage R.: Stone in Architecture: Properties, Durability, Fourth Edition, 2011, Pages 1552, Springer-Verlag Berlin. Heidelberger Platz 3. D-14197 Berlin, Germany.

19. Luhmann A.J., Kong X.-Z., Tutolo B.M., Garapati N., Bagley B.C., Saar M.O., Seyfried Jr. W.E.: Experimental dissolution of dolomite by $\mathrm{CO} 2$-charged brine at $100^{\circ} \mathrm{C}$ and 150 bar: Evolution of porosity, permeability, and reactive surface area. Chemical Geology, Vol. 380, 2014, Pages 145-160.

20. Feng M., Wu P., Qiang Z., Liu X., Duan Y., Xia M.: Hydrothermal dolomite reservoir in the Precambrian Dengying Formation of central Sichuan Basin, Southwestern China. Marine and Petroleum Geology, Vol. 82, 2017, Pages 206-219.

21. Fjaer E., Holt R.M., Horsrud P., Raaen A.M., Rines R.: Petroleum Related Rock Mechanics. 2nd edition, Vol. 53, Elsevier. Amsterdam, 2008.

22. Schön J.H.: Chapter 7 - Geomechanical Properties. Handbook of Petroleum Exploration and Production, Vol. 8, 2011, Pages 245-271.

23. Wierzbicki M., Młynarczuk M.: Structural aspects of gas and dolomite outburst in Rudna copper mine. International Journal of Rock Mechanics and Mining Sciences, Vol. 57, 2013, Pages 113-118.

24. Pajdak A., Godyń K., Kudasik M., Murzyn T.: The use of selected research methods to describe the pore space of dolomite from copper ore mine, Poland. Environmental Earth Sciences, Vol. 76, 2017, 389.

25. Pajdak A., Kudasik M.: Structural and textural characteristic of selected copper-bearing rocks as one of the elements aiding in the assessment of gasogeodynamic hazard. Studia Geotechnica et Mechanica, Vol. 39, Issue 2, 2017, Pages 51-59. 
26. Niesyt M., Szydłak T., Wyszomirski P., Wodnicka K.: The structural and textural characteristics of certain Polish dolostones affecting their decarbonatization. Bulletin of the Mineral and Energy Economy Research Institute of the Polish Academy of Sciences, Vol. 83, 2012, Pages 121-129.

27. Rouquerol J., Avnir D., Fairbridge C.W., Everett D.H., Haynes J.H., Pernicone N., Ramsay J.D.F., Sing K.S.W., Unger K.K.: Recommendations for the characterization of porous solids (technical report). Pure and Applied Chemistry, Vol. 66, Issue 8, 1994, Pages 1739-1758.

28. Skoczylas N., Kudasik M., Wierzbicki M., Murzyn T.: New instruments and methods for analysing the coalmethane system. Studia Geotechnica et Mechanica, Vol. 37, No. 1, 2015, Pages 85-92.

29. Szlązak N., Korzec M.: Method for determining the coalbed methane content with determination the uncertainty of measurements. Archives of Mining Sciences, Vol. 61, Issue 2, 2016, Pages 443-456.

30. Washburn E.W.: The dynamics of capillary flow. Physical Review, Vol. 17, Issue 3, 1921, Pages 273-283.

31. Kudasik M., Skoczylas N.: Analyzer for measuring gas contained in the pore space in rocks. Measurement Science and Technology, Vol. 28, No. 10, 2017, 105901.

32. Kudasik M., Skoczylas N.: Balancing the amount and composition of gas contained in the pore space of cupriferous rocks. Environmental Earth Sciences, Vol. 77, 2018, 135.

33. Kudasik M., Skoczylas N., Murzyn T., Wierzbicki M.: The effectiveness of the rock comminution process in the light of evaluating gas content in rocks. Transactions of The Strata Mechanics Research Institute, Vol. 16, Issue 3-4, 2014, Pages 81-84.

34. ISO13320-1:1999(E): Particle size analysis - Laser scattering methods - Part 1: General principles, 1999.

35. Jillavenkatesa A., Dapkunas S.J., Lum L-S.H.: Particle Size Characterization. NIST Special Publication, $960-$ $1,2001$. 